\title{
Genotype by environment interaction for activity-based estrus traits in relation to production level for Danish Holstein
}

\author{
Ahmed Ismael, ${ }^{\dagger} \dagger^{1}$ Erling Strandberg, $†$ Britt Berglund, $\dagger$ Morten Kargo, ${ }^{\star} \ddagger$ Anders Fogh, $\ddagger$ and Peter Løvendahl ${ }^{*}$ \\ ${ }^{*}$ Center for Quantitative Genetics and Genomics, Department of Molecular Biology and Genetics, Aarhus University, PO Box 50, \\ DK-8830 Tjele, Denmark \\ †Department of Animal Breeding and Genetics, Swedish University of Agricultural Sciences, PO Box 7023, SE-750 07 Uppsala, Sweden \\ ‡Knowledge Center for Agriculture (SEGES), DK-8200 Aarhus N, Skejby, Denmark
}

\begin{abstract}
The objective of this study was to investigate whether genotype by environment interaction exists for female fertility traits and production of energy-corrected milk at $70 \mathrm{~d}$ in milk (ECM70). Fertility traits considered were the activity-based estrus traits interval from calving to first high activity (CFHA), duration of high activity episode (DHA), as an indicator for first estrus duration, and strength of high activity episode (SHA), as an indicator for first estrus strength. The physical activity traits were derived from electronic activity tags for 11,522 first-parity cows housed in 125 commercial dairy herds. Data were analyzed using a univariate random regression animal model (URRM), by regressing the phenotypic performance on the average herd ECM70 as an environmental gradient. Furthermore, the genetic correlations between CFHA and ECM70 as a function of production level were estimated using a bivariate random regression animal model (BRRM). For all traits, heterogeneity of additive genetic variances and heritability estimates was observed. The heritability estimate for CFHA decreased from 0.25 to 0.10 with increasing production level and the heritability estimate for ECM70 decreased from 0.35 to 0.15 with increasing production level using URRM. The genetic correlation of the same trait in low and high production levels was around 0.74 for CFHA and 0.80 for ECM70 using URRM, but when data were analyzed using the multiple-trait analysis (MT), genetic correlation estimates between low and high production levels were not significantly different from unity. Furthermore, the genetic correlation of SHA between low and high production level was 0.22 using URRM, but the
\end{abstract}

\footnotetext{
Received May 11, 2016.

Accepted August 2, 2016.

${ }^{1}$ Corresponding author: ahmed.ismael@mbg.au.dk or ahmed ismaelsayed@gmail.com
}

corresponding correlation estimate had large standard error when data were analyzed using MT. The genetic correlation between CFHA and ECM70 as a function of production environment was weak but unfavorable and decreased slightly from 0.09 to 0.04 with increasing production level using BRRM. Moreover, the same trend was observed when the data were analyzed using MT where the genetic correlation between CFHA and ECM70 in the low production environment was 0.29 compared with -0.13 in the high production environment, but these estimates had large standard errors. In conclusion, regardless of the trait used, in relation to average herd ECM70 production, the results indicated no clear evidence of strong genotype by environment interaction that would cause significant re-ranking of sires between low and high production environments.

Key words: activity-based estrus traits, female fertility, genotype by environment interaction, random regression model

\section{INTRODUCTION}

Dairy cow fertility is becoming increasingly important throughout the world because it has a substantial effect on the overall profitability of dairy cattle. For that reason, selection indices worldwide have changed from the previous focus on yield to a more balanced breeding approach that includes longevity, udder health, and fertility (Miglior et al., 2005). An increasing number of countries are performing genetic evaluations for female fertility, and in August 2015, 21 countries were included in the international genetic evaluation for female fertility (Interbull, 2015). This wide range of environments increases the concerns of possible genotype by environment interaction $(\mathbf{G} \times \mathbf{E})$, which might lead to a change in the performance of animals and their offspring between the environments where they are selected and where they are used (Falconer and Mackay, 1996). 
Genotype by environment interaction exists when the ability to alter the phenotype in response to changes in the environment differs among animals (Falconer and Mackay, 1996). Recently, reaction norm models have been used to describe effects that change gradually over a continuous scale (de Jong, 1995; Falconer and Mackay, 1996) where the genotype effect is modeled as a function of a continuous environmental scale, which results in heterogeneous variance components and heritabilities that change with the environmental gradient (Kolmodin et al., 2002; Ravagnolo and Misztal, 2002b; Strandberg et al., 2009). The reaction norm model is similar to the random regression test day models used in dairy cattle breeding (Schaeffer, 2004), but the covariate used is the environmental gradients instead of DIM.

Although the previous studies indicated that expression of fertility is sensitive to environmental components such as seasons and climatic factors (Ravagnolo and Misztal, 2002b; Oseni et al., 2004; Boonkum et al., 2011; Ismael et al., 2016) and milk production level (Ravagnolo and Misztal, 2002a), few studies have been performed on $\mathrm{G} \times \mathrm{E}$ for female fertility within a country, and these studies found little evidence of $\mathrm{G} \times \mathrm{E}$ as most of the genetic correlations between environments were close to unity. Kolmodin et al. (2002) used a random regression model to study $\mathrm{G} \times$ $\mathrm{E}$ for days open in Nordic Red dairy breeds where the environmental scale was defined as herd year average of protein yield, and they found a large heterogeneity of genetic variance. Furthermore, the heritability estimates of days open increased as herd year average protein increased and ranged from 0 to 0.35 . Strandberg et al. (2009) used the herd average production to study $\mathrm{G} \times \mathrm{E}$ for the interval from calving to first insemination (CFI) and calving interval in UK Holstein cows and found a slightly higher heritability for both traits at low production level compared with high production level. Haile-Mariam et al. (2008) used average herd lactation milk yield as the continuous environmental descriptor to study $\mathrm{G} \times \mathrm{E}$ in Holstein cows in Australia and found that heritability of CFI decreased with increasing production-heritability of CFI in low production environment was higher than the heritability in high production environment. On the other hand, heritability estimates for calving interval and first service nonreturn rate were homogeneous across production environments. Furthermore, the low genetic correlations found between low and high production environments were associated with large standard errors and thus there was no conclusive evidence of the existence of significant $\mathrm{G} \times \mathrm{E}$, causing re-ranking of bulls across production environments for both traits.
One of the main problems hindering the genetic improvement for better fertility in dairy cattle is the antagonistic genetic correlation between production and fertility traits, indicating that selection for increased production reduces reproductive efficiency (Berry et al., 2003; König et al., 2008; Sewalem et al., 2010). However, the unfavorable genetic correlation between yield and fertility was not constant across different environments. For example, Kolmodin et al. (2002) used a multiple-trait random regression model to investigate the heterogeneity of the genetic correlation between days open and protein yield, using the average herd protein production as environmental descriptor. They found a decrease in the genetic correlation with increasing protein production. This implies that the unfavorable genetic correlation between production and fertility can be alleviated by improving the production environment. However, in contradiction, Haile-Mariam et al. (2008) found that the genetic correlation between CFI and milk yield increased with increasing production environment, using the average milk yield as an environmental descriptor.

The previous studies on $\mathrm{G} \times \mathrm{E}$ for fertility traits were performed based on AI data, and the decision of when and how many times to inseminate cows is done by the farmer. This decision could be influenced by factors that vary from cow to cow (e.g., based on the cow's milk yield). This may influence the genetic parameters such as heritability of fertility traits and the genetic correlations between yield and fertility traits. However, the development of some new technologies makes it possible to record new fertility traits that are free from farmer interventions. This may alleviate human bias on all estimates of genetic parameters and may thus provide higher heritability estimates than the traditional measures. For example, CFI is the traditional measure of the return to cyclic estrus after calving and the heritability estimate of this trait in Holstein cows in Nordic countries is only 0.05 (SEGES, 2015). On the other hand, the interval from calving to first high activity episode (CFHA) is an objective measure of return to cyclicity after calving and it can be measured by activity tags. This trait has heritability estimates of 0.12 to 0.18 (Løvendahl and Chagunda, 2009; Ismael et al., 2015), which is higher than CFI. In addition, these devices are found to be useful to measure other estrus-related traits [e.g., strength of first high activity episode (SHA) and duration of high activity episode (DHA) as an indicator of estrus strength and estrus duration, respectively (Løvendahl and Chagunda, 2009; Ismael et al., 2015)]. These traits are not routinely recorded in most current breeding programs, but could be useful for improving the ability to detect cows displaying estrus behavior. Moreover, the higher heritability 
estimate of CFHA and the already widespread use of activity tags for estrus detection makes it important to evaluate the relationship between fertility and yield traits using fertility measure that is free of human bias. Furthermore, it is also important to investigate how the estimates of genetic correlation between yield and fertility measure vary over a trajectory of environmental descriptors defined through herd milk yield, to indicate the $\mathrm{G} \times \mathrm{E}$ effects.

The objectives of this study were to estimate genetic parameters of fertility traits derived from activity tags (interval from calving to first high activity, and duration and strength of the first high activity episode), and estimate the genetic correlation between the interval from calving to first high activity and ECM, as a function of production level expressed as average herd ECM in Danish Holstein cows.

\section{MATERIALS AND METHODS}

\section{Design, Animals, and Data}

Female fertility traits in the present study were CFHA (Løvendahl and Chagunda, 2010; Ismael et al., 2015), as well as duration and strength of the first high activity episode after calving (DHA and SHA), all based on data from physical activity meters. The physical activity traits were based on raw data of 42,096 Danish Holstein cows collected from January 2010 to January 2015 housed in 164 commercial dairy herds with automatic milking systems and electronic activity tags fitted on neckbands (Lely Qwes H or HR, Lely Industries BV, Maassluis, the Netherlands). Cows' physical activity information was measured as the number of electronic impulses per 2-h bin initiated by changes in acceleration due to head and neck movements. Data were edited using the procedure as described by Ismael et al. (2015). Only records from cows in the first parity were included in the analysis. To be eligible for inclusion in the analysis, physical activity recording had to include the period from 15 to $155 \mathrm{~d}$ postpartum. Within this period, every cow had to have at least 45 consecutive days of recorded activity. This rule was applied because farms had different start times in the physical activity recording. Furthermore, cows with age at first calving outside the range of 500 to $1,100 \mathrm{~d}$ were removed from the analysis. Three activity-based estrus traits were defined as follows: $\mathrm{CFHA}=$ number of days from calving to day of first high activity, DHA = time in hours between start and end of the first high activity episode, and SHA = the mean of the 2 highest deviation values during the first high activity episode; SHA was ln-transformed after adding 1.0 before statistical analysis. After editing, the data set with activity based estrus traits contained 11,522 first-parity cows housed in 125 commercial dairy herds. From these herds, testday data records for milk, fat, and protein yields of Holstein cows calving between 2008 and 2015 were obtained. From these records, only test days close to $70 \pm$ 15 DIM for lactations 1 to 3 were selected, because it is close to the peak milk yield. If the cow had more than one test day during this period, only the earlier record was used. This editing produced a data set containing 65,834 production records for 34,765 cows from first 3 lactations from 125 commercial dairy herds. Thereafter, ECM at DIM 70 (ECM70) was calculated as $(0.3246 \times \mathrm{kg}$ of milk $)+(12.86 \times \mathrm{kg}$ of fat $)+(7.04 \times$ $\mathrm{kg}$ of protein) (Smith et al., 2002). This data set was used to obtain herd solutions of ECM70 for the later use as an environmental descriptor. From these records, the first-lactation records were merged with the fertility data set. The final data set contained activity traits for 11,522 first-parity cows housed in 125 commercial dairy herds. Of these, 10,009 cows also had phenotypic records of ECM70. The pedigree was built using siredam structure and tracing back as many generations as possible in the Nordic Cattle database (NAV, Skejby, Denmark). The total pedigree file included 98,927 animals.

\section{Statistical Analysis}

The first analysis was a fixed effects model to obtain herd solutions for ECM70 to be used as an environmental descriptor. Solutions were obtained using the HPMIXED procedure in the SAS package (SAS 9.3, SAS Institute Inc., Cary, NC) using the following model:

$$
\mathrm{y}_{i j k}=\mu+h_{i}+p_{j}+y m_{k}+\mathrm{e}_{i j k}
$$

where $\mathrm{y}_{i j k}$ is the ECM70 for cow $m$ in the herd $i$, parity $j$, calving during the year-month of calving $k ; \mu$ is the intercept; $h_{i}$ is the fixed effect of herd $i(i=125$ herds); $p_{j}$ is the fixed effect of parity $j(j=1$ to 3$) ; y m_{k}$ is the fixed effect of year-month $k$ of calving ( $k=76$ levels), and $\mathrm{e}_{i j k}$ is the random residual, which assumed to be normally distributed with distribution $\sim \mathrm{ND}\left(0, \mathrm{I} \sigma_{\mathrm{e}}^{2}\right)$ where $I$ is the identity matrix and $\sigma^{2}{ }_{e}$ is the residual variance.

Herd solutions from model [1] were standardized to mean $=0$ and ranging from -1 to +1 before being used as a continuous environmental descriptor in the random regression model (Schaeffer, 2004). The standardized environmental scale (PL) was derived as

$$
\mathrm{PL}=\frac{2\left(\mathrm{H}-\mathrm{H}_{\mathrm{Min}}\right)}{\mathrm{H}_{\mathrm{Max}}-\mathrm{H}_{\mathrm{Min}}}-1,
$$


Table 1. Means, SD, and minimum and maximum values of the traits and environmental descriptor before standardization

\begin{tabular}{|c|c|c|c|c|}
\hline Trait or environment ${ }^{1}$ & Mean & $\mathrm{SD}$ & Minimum & Maximum \\
\hline CFHA (d) & 42 & 25.5 & 15 & 155 \\
\hline DHA (h) & 8.9 & 3.0 & 6.0 & 26 \\
\hline SHA (ln-units) & 1.08 & 0.45 & 0.01 & 2.9 \\
\hline ECM70 $(\mathrm{kg})$ & 33.4 & 6.07 & 3.9 & 59.4 \\
\hline Herd average ECM70 $(\mathrm{kg})$ & 39.4 & 2.9 & 32.4 & 46.6 \\
\hline
\end{tabular}

${ }^{1} \mathrm{CFHA}=$ interval from calving to first high activity; DHA = duration of high activity; SHA = strength of high activity is based on the log-transformed mean of the 2 highest deviations between standardized activity and the smoothed activity ratio; ECM70 = ECM production at DIM 70; Herd average (ECM70) = herd solutions of ECM production at DIM 70.

where $\mathrm{H}$ is the herd ECM solution, $\mathrm{H}_{\mathrm{Min}}\left(\mathrm{H}_{\mathrm{Max}}\right)$ is the minimum (maximum) herd ECM solution represented in the data. Descriptive statistics of the traits and the environmental descriptor before the standardization step are shown in Table 1.

\section{Random Regression Analysis}

Genetic analysis was performed with the average information REML procedure as implemented in the DMU package (Madsen and Jensen, 2010). Univariate random regression analysis (URRM) was performed to estimate the variance components, for each trait (CFHA, DHA, SHA, and ECM70) separately. Bivariate random regression analysis (BRRM) was performed to estimate genetic correlations between the CFHA and ECM70. The following random regression animal model was used for the analysis

$$
\mathrm{y}_{i j k}=\mu+h_{i}+b(A G E)+y m_{j}+\mathbf{x}^{\prime} \mathbf{a}+\mathrm{e}_{i j k},
$$

where $\mathrm{y}_{i j k}$ is the observation of the traits CFHA, DHA, SHA, or ECM70; $\mu$ is the intercept; $h_{i}$ is the fixed effect of herd $i(i=125$ herds $) ; b(A G E)$ is the fixed regression of the traits on age at first calving; $y m_{j}$ is the fixed effect of year-month combination of high activity episode $(j=60$ levels), for CFHA, DHA, and SHA or the fixed effect of year-month of calving for the trait ECM70 $(j$ $=58$ levels $) ; \mathbf{a}$ is a column vector of $\left[\mathrm{a}_{0 \mathrm{k}}, \mathrm{a}_{1 \mathrm{k}}\right]^{\prime}$, where the element $\mathrm{a}_{0 k}$ is the additive genetic effect (level) for the cow $k$ and $\mathrm{a}_{1 k}$ is the linear random regression coefficient for cow $k$ on the herd ECM70 production level $(\mathrm{PL}), \mathrm{x}^{\prime}$ is a row vector with elements 1 and $\mathrm{PL}$ for the herd of this cow; with assumptions $\sim \mathrm{ND}\left(0, \mathrm{~A} \otimes \mathrm{V}_{\mathrm{a}}\right)$, where $\mathbf{A}$ is the numerator relationship matrix, $\mathbf{V}_{\mathrm{a}}$ is defined below, and $\mathrm{e}_{i j k}$ is the random residual, $\sim \mathrm{ND}(0$, $\left.I \sigma_{e}^{2}\right)$. The genetic variance for a given ECM production level (PL) was calculated as $\sigma_{\mathrm{a} \mid \mathrm{PL}}^{2}=\mathrm{x}^{\prime} \mathbf{V}_{\mathrm{a}} \mathbf{x}$, where $\mathbf{V}_{\mathrm{a}}$ calculated as

$$
\mathrm{V}_{\mathrm{a}}=\left(\begin{array}{cc}
\sigma_{\mathrm{a} 0}^{2} & \sigma_{\mathrm{a} 0, \mathrm{a} 1} \\
\sigma_{\mathrm{a} 1, \mathrm{a} 0} & \sigma_{\mathrm{a} 1}^{2}
\end{array}\right),
$$

where $\sigma_{\mathrm{a} 0}^{2}$ is the additive genetic variance for the level, $\sigma_{\mathrm{a} 1}^{2}$ is the additive genetic variance for the slope, and $\sigma_{\mathrm{a} 0, \mathrm{a} 1}$ is the additive genetic covariance between the level and the slope. The heritability of the trait for a given ECM production level was calculated as

$$
\mathrm{h}_{\mathrm{PL}}^{2}=\frac{\sigma_{\mathrm{a} \mid \mathrm{PL}}^{2}}{\sigma_{\mathrm{a} \mid \mathrm{PL}}^{2}+\sigma_{\mathrm{e}}^{2}} .
$$

For the BRRM, the additive genetic covariance between CFHA and ECM70 for a given ECM production level was calculated as $\sigma_{1,2 \mid \mathrm{PL}}=\mathbf{x}^{\prime} \mathbf{C O V}_{\mathbf{1 , 2}} \mathbf{x}$, where $\mathbf{C O V}_{\mathbf{1 , 2}}$ was calculated as

$$
\mathbf{C O V}_{1,2}=\left(\begin{array}{ll}
\sigma_{\mathrm{a} 0 \mathrm{ECM}, \mathrm{a} 0 \mathrm{CFHA}} & \sigma_{\mathrm{a} 0 \mathrm{ECM}, \text { a1 CFHA }} \\
\sigma_{\mathrm{a} 1 \mathrm{ECM}, \text { a0 CFHA }} & \sigma_{\mathrm{a} 1 \mathrm{ECM}, \mathrm{a} 1 \mathrm{CFHA}}
\end{array}\right),
$$

where $\sigma_{\mathrm{a} 0 \mathrm{ECM}}$, a $\mathrm{CFHA}$ is the additive genetic covariance between the level of ECM and the level of CFHA, $\sigma_{\mathrm{a} 0 \mathrm{ECM}, \mathrm{a} 1 \mathrm{CFHA}}$ is the additive genetic covariance between the level of ECM and the slope of CFHA, $\sigma_{\mathrm{a} 1 \mathrm{ECM}, \mathrm{a} 0 \mathrm{CFHA}}$ is the additive genetic covariance between the slope of ECM and the level of CFHA, and $\sigma_{\mathrm{a} 1 \mathrm{ECM}, \mathrm{a} 1 \mathrm{CFHA}}$ is the additive genetic covariance between the slope of ECM and the slope of CFHA.

The genetic correlation between CFHA and ECM70 for a given ECM production level was calculated as

$$
\mathrm{r}_{\mathrm{a}}=\frac{\sigma_{1,2} \mid \mathrm{PL}}{\sigma_{\mathrm{a} 1 \mid \mathrm{PL}} \times \sigma_{\mathrm{a} 2 \mid \mathrm{PL}}}
$$

where $\sigma_{\mathrm{a} 1 \mid \mathrm{PL}}$ is the additive genetic standard deviation of CFHA for a given ECM production level, and $\sigma_{\mathrm{a} 2 \mid \mathrm{PL}}$ is the additive genetic standard deviation of ECM70 for a given ECM production level.

The residual variance-covariance matrix for the BRRM model is 


$$
\operatorname{Var}(e)=\mathbf{R}=\left[\begin{array}{cc}
\sigma_{e_{1}}^{2} & \sigma_{e_{1} e_{2}} \\
\sigma_{e_{2} e_{1}} & \sigma_{e_{2}}^{2}
\end{array}\right],
$$

where $\mathbf{R}$ is the residual covariance matrix, and $\sigma_{e_{1}}^{2}, \sigma_{e_{2}}^{2}$ are the residual variances for CFHA and ECM70; and $\sigma_{e_{1} e_{2}}$ is the residual covariance between CFHA and ECM70.

The heterogeneity of residual variances was studied by calculating the variance of residuals for observations grouped in 3 classes of the production environment. These classes were determined by sorting the data based on the production environment, each class approximately containing one-third of the observations (lowest, average, and highest third of production environments, respectively). These calculated residual variances were checked visually for any trend across environments. Standard errors of heritability estimates obtained from the URRM analysis were calculated using a Taylor series expansion approximation (Dodenhoff et al., 1998).

\section{Multiple-Trait Analysis}

For the further validation of the URRM analysis, a multiple-trait analysis (MT) was carried out where the production environment was categorized into low or high production (observations from approximately the lowest and highest third of production environments, respectively), where the numbers of records were 3,786 and 3,899 in the lowest and highest production environments, respectively. The average values of the traits and the environmental descriptor for the 2 environments are shown in Table 2. For the validation of the URRM, the trait values were then considered as 2 separate traits and analyzed using the following model in a bivariate animal model:

$$
\mathrm{y}_{i j k}=\mu+h_{i}+b(A G E)+y m_{j}+a_{k}+\mathrm{e}_{i j k},
$$

where all model terms are as in [2] and $a_{k}$ is the breeding value for cow $k$ in the given environment. The variancecovariance structure for this model is

$$
\operatorname{Var}\left[\begin{array}{l}
\mathbf{a}_{1} \\
\mathbf{a}_{2}
\end{array}\right]=\left[\begin{array}{cc}
\mathbf{A} \sigma_{a_{1}}^{2} & \mathbf{A} \sigma_{a_{1} a_{2}} \\
\mathbf{A} \sigma_{a_{2} a_{1}} & \mathbf{A} \sigma_{a_{2}}^{2}
\end{array}\right],
$$

where $\mathbf{a}_{1}$ and $\mathbf{a}_{2}$ represent the additive genetic merit of the cow in low- and high-producing herds (environments), respectively, $\sigma_{a_{1}}^{2}, \sigma_{a_{2}}^{2}$ are the additive genetic variances for the traits in these environments; and $\sigma_{a_{1} a_{2}}$ is the additive genetic covariance for the trait across environments. Because the correlated traits are not recorded on the same animals, no environmental covariance exists between traits and the residual variancecovariance matrix is

$$
\operatorname{Var}(e)=\mathbf{R}=\left[\begin{array}{cc}
\sigma_{e_{1}}^{2} & 0 \\
0 & \sigma_{e_{2}}^{2}
\end{array}\right],
$$

where $\mathbf{R}$ is the residual variance-covariance matrix, and $\sigma_{e_{1}}^{2}, \sigma_{e_{2}}^{2}$ are the residual variances for the trait in low and high production environments. Genetic correlations are considered significantly different from unity if they deviate by more than $1.645 \times$ standard error from 1 , and used as an indication of $\mathrm{G} \times \mathrm{E}$, where the value 1.645 corresponds to the one-sided $5 \%$ cut-off point of the normal distribution.

For the validation of BRRM between CFHA and ECM70 in low and high production environments, 2 separate analyses were performed to estimate the genetic correlation between CFHA and ECM70 in low and high production, respectively. The same model [3] was used, but the variance-covariance structure for this model was

$$
\operatorname{Var}\left[\begin{array}{l}
\mathbf{a}_{1} \\
\mathbf{a}_{2}
\end{array}\right]=\left[\begin{array}{cc}
\mathbf{A} \sigma_{a_{1}}^{2} & \mathbf{A} \sigma_{a_{1} a_{2}} \\
\mathbf{A} \sigma_{a_{2} a_{1}} & \mathbf{A} \sigma_{a_{2}}^{2}
\end{array}\right],
$$

where $\mathbf{a}_{1}$ and $\mathbf{a}_{2}$ represent the additive genetic merit of the cow for CFHA and ECM70 in a given production environment (low or high), $\sigma_{a_{1}}^{2}, \sigma_{a_{2}}^{2}$ are the additive genetic variances for CFHA and ECM70 in low or high production environments; and $\boldsymbol{\sigma}_{\mathrm{a} 1 \mathrm{a} 2}$ is the additive genetic covariance between CFHA and ECM70 in low or high production environments. Because both traits are recorded on the same animal, the environmental covariance exists between traits and the residual variancecovariance matrix is

$$
\operatorname{Var}(e)=\mathbf{R}=\left[\begin{array}{cc}
\sigma_{e_{1}}^{2} & \sigma_{e_{1} e_{2}} \\
\sigma_{e_{2} e_{1}} & \sigma_{e_{2}}^{2}
\end{array}\right],
$$

where $\mathrm{R}$ is the residual covariance matrix, and $\sigma_{e_{1}}^{2}, \sigma_{e_{2}}^{2}$ are the residual variances for CFHA and ECM70 in low or high production environments; and $\sigma_{e_{1} e_{2}}$ is the residual covariance between CFHA and ECM70 in low or high production environments. 
Table 2. Means, SD, and minimum and maximum values of the traits and the average value of the environmental descriptor after standardization in the lowest and highest $33 \%$ of the data set in the multiple-trait analysis

\begin{tabular}{lcccc}
\hline Trait or environment $^{1}$ & Mean & SD & Minimum & Maximum \\
\hline CFHA $_{\text {low }}(\mathrm{d})$ & 41.7 & 26.6 & 15 & 155 \\
$\mathrm{CFHA}_{\text {high }}$ (d) & 42.3 & 25.0 & 15 & 154 \\
$\mathrm{DHA}_{\text {low }}(\mathrm{h})$ & 8.8 & 2.9 & 6 & 26 \\
$\mathrm{DHA}_{\text {high }}(\mathrm{h})$ & 8.9 & 3.0 & 6 & 24 \\
$\mathrm{SHA}_{\text {low }}(\mathrm{ln}-\mathrm{units})$ & 1.05 & 0.45 & 0.03 & 2.7 \\
$\mathrm{SHA}_{\text {high }}$ (ln-units) & 1.07 & 0.45 & 0.02 & 2.9 \\
ECM70 $_{\text {low }}(\mathrm{kg})$ & 30.8 & 5.8 & 3.9 & 56.3 \\
ECM70 $_{\text {high }}(\mathrm{kg})$ & 35.9 & 5.8 & 6.8 & 57 \\
Environmental scale $_{\text {low }}(\mathrm{kg})$ & 36.6 & - & - & - \\
Environmental scale $_{\text {high }}(\mathrm{kg})$ & 42.3 & - & - & - \\
\hline
\end{tabular}

${ }^{1}$ CFHA = interval from calving to first high activity; DHA = duration of high activity; SHA = strength of high activity is based on the log-transformed mean of the 2 highest deviations between standardized activity and the smoothed activity ratio; ECM70 = ECM production at DIM 70; Environmental scale = average value of the environmental scale before standardization.

\section{RESULTS}

\section{Descriptive Statistics}

Overall means, standard deviations, and minimum and maximum for the physical activity traits are summarized in Table 1. The average values of the traits and the environmental descriptor before standardization for the low and high production environments (lowest and highest third of the production environments) are shown in Table 2. The effect of production environment on estrus-related traits was very small and statistically nonsignificant, whereas the average cow ECM70 in the high production environment was $35.9 \mathrm{~kg}$ compared with $30.8 \mathrm{~kg}$ in the low production environment.

\section{Variance Components and Heritability Estimates from URRM}

The parameter estimates of the URRM are shown in Table 3. The URRM including DHA did not converge because the high genetic correlation between level and slope estimate. From the standard errors of the estimates, the genetic variance components of level and slope of the random regression were significantly dif- ferent from zero for CFHA, SHA, and ECM70, indicating $\mathrm{G} \times \mathrm{E}$ with respect to the herd average ECM70, whereas the URRM analysis failed to converge in case of DHA. The genetic correlations between the level and the slope for CFHA and ECM70 against the production environment were negative $(-0.33$ and -0.47$)$, which means cows with genetically shorter CFHA or produce less ECM70 will be more sensitive to the changes in the herd production level. On the other hand, the genetic correlations between the level and slope against the production environment for SHA were not significantly different from zero.

The additive genetic variance and the heritability estimates for CFHA as a function of production level are shown in Figure 1. The additive variance in the lowest herd environment was twice the variance in the highest herd environment. Heritability estimates for CFHA decreased with increasing production level from 0.25 to a minimum value of 0.10 when production levels were slightly above average before increasing slightly to 0.15 in the end of the environmental trajectory, with a heritability of 0.11 in the average environment with standard errors between 0.02 in the average environment and 0.04 and 0.05 in the highest and lowest environmental scale, respectively.

Table 3. Estimates of variance components of level, slope $\left(\sigma_{a 0}^{2}, \sigma_{a 1}^{2}\right)$, covariance between level and slope $\left(\sigma_{\text {a0a1 }}\right)$, correlation between level and slope $\left(r_{\mathrm{a} 0, \mathrm{a} 1}\right)$, residual variance $\left(\sigma_{\mathrm{e}}^{2}\right)$ with their SE in parentheses, and heritability $\left(\mathrm{h}^{2}\right.$, in average environment) from single trait random regression model for estrus-related traits and ECM production at DIM 70 (ECM70)

\begin{tabular}{|c|c|c|c|c|c|c|}
\hline Trait $^{1}$ & $\sigma_{\mathrm{a} 0}{ }^{2}$ & $\sigma_{\mathrm{a} 1}^{2}$ & $\sigma_{\mathrm{a} 0 \mathrm{a} 1}$ & $\mathrm{r}_{\mathrm{a} 0, \mathrm{a} 1}$ & $\sigma_{\mathrm{e}}^{2}$ & $\mathrm{~h}^{2}$ \\
\hline DHA* & $0.23(0.08)$ & $0.0002(0.2)$ & $-0.006(0.08)$ & $-0.99(712)$ & 8.3 & $0.03(0.01)$ \\
\hline
\end{tabular}

${ }^{1} \mathrm{CFHA}=$ interval from calving to first high activity; DHA = duration of high activity; SHA = strength of high activity is based on the logtransformed mean of the two highest deviations between standardized activity and the smoothed activity ratio.

*The analysis did not converge because of a genetic correlation very close to unity. 


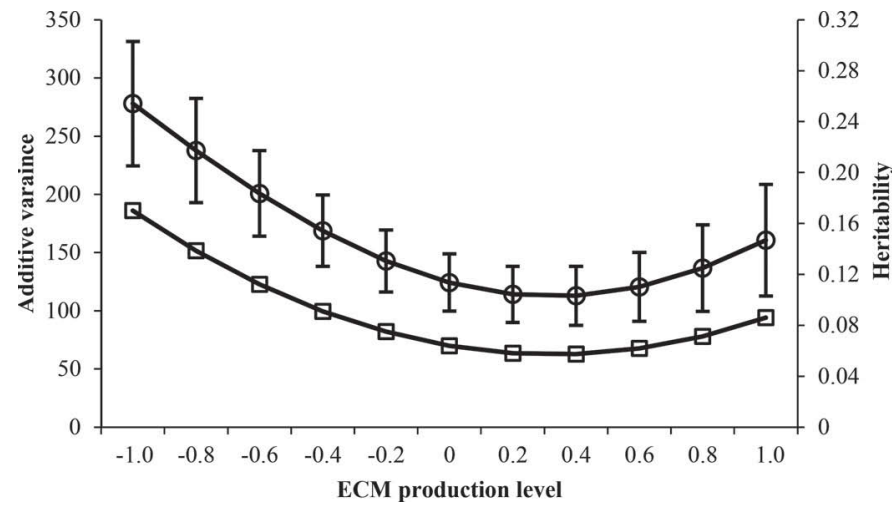

Figure 1. Additive genetic variance (white squares) and heritability estimates (white circles) for the interval from calving to first high activity $\pm \mathrm{SE}$ as a function of average herd ECM.

Because the reaction norm slope for DHA was not significantly different from zero, the additive genetic variance and the heritability remained constant over the environmental scale. For SHA, the additive genetic variance and heritability estimates decreased as a function of the environment in the URRM (not shown). Heritability decreased from 0.12 in the lowest environment to the minimum estimate of 0.03 in the average environment before increasing to 0.13 in the end of the environmental scale with standard errors between 0.01 in the average environment and 0.05 in the lowest and highest environmental scale.

The additive genetic variance and the heritability estimates for ECM70 as a function of production level are shown in Figure 2. The additive variance in the lowest herd environment was more than twice the variance in the highest herd environment. Heritability estimates for ECM70 decreased with increasing the production level from 0.36 in the beginning of the environmental scale to a minimum value of 0.15 , slightly above the av-

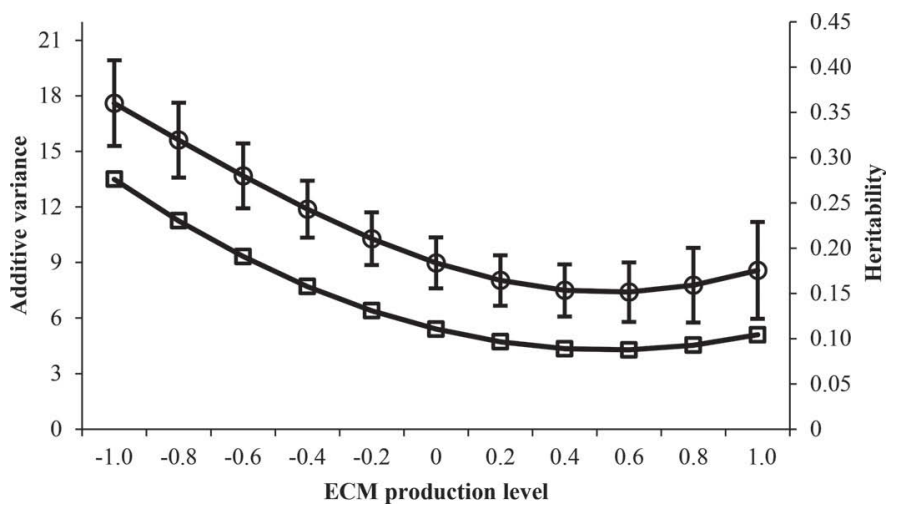

Figure 2. Additive genetic variance (white squares) and heritability estimates (white circles) for the ECM at DIM $70 \pm$ SE as a function of average herd ECM.

erage production environment before increasing slightly to 0.18 in the highest production environment.

In general, the change in the variance components, heritabilities, and genetic correlations between low and high production levels was detected by MT analysis and URRM (Table 4), although the actual point estimates were not identical. Both models also detected strong $\mathrm{G} \times \mathrm{E}$ for SHA, but weaker for the other traits. However, the MT model including ECM70 failed to converge, most likely due to high genetic correlations between environments.

\section{Results of BRRM Analysis of CFHA and ECM70}

In the BRRM, the correlations between reaction norm levels and slopes against the production level were very small and statistically nonsignificant with large standard errors (Table 5). Genetic correlation between CFHA and ECM70, as a function of the herd production level is shown in Figure 3. The genetic correlation

Table 4. Estimates of variance components, heritabilities, genetic correlations, and their SE across environments from the bivariate analysis (MT) treating the trait in low and high production levels as different traits and from univariate random regression model (URRM) between the average environmental values in low and high production levels

\begin{tabular}{lccccc}
\hline Trait $^{1}$ & \multicolumn{1}{c}{$\sigma_{a}^{2}$} & $\sigma_{e}{ }^{2}$ & $\mathrm{~h}^{2} \mathrm{MT}$ & $\mathrm{h}^{2} \mathrm{URRM}^{2}$ & $r_{a} \mathrm{MT}$ \\
CFHA $_{\text {low }}$ & $78.4(24.0)$ & $583(24.5)$ & $0.12(0.04)$ & $0.15(0.03)$ & $0.90(0.16)$ \\
CFHA $_{\text {high }}$ & $51(17.20)$ & $548(19.0)$ & $0.09(0.03)$ & $0.10(0.02)$ & $0.84(0.46)$ \\
DHA $_{\text {low }}$ & $0.42(0.20)$ & $7.8(0.25)$ & $0.05(0.02)$ & $0.03(0.01)$ & 0.74 \\
DHA $_{\text {high }}$ & $0.16(0.13)$ & $8.5(0.23)$ & $0.02(0.02)$ & $0.03(0.01)$ & $0.08(0.34)$ \\
SHA $_{\text {low }}$ & $0.012(0.006)$ & $0.18(0.007)$ & $0.06(0.03)$ & $0.04(0.02)$ & 0.22 \\
SHA $_{\text {high }}$ & $0.01(0.005)$ & $0.19(0.007)$ & $0.05(0.02)$ & $0.04(0.02)$ & $1.00^{*}$ \\
ECM70 $_{\text {low }}$ & $5.5(1.40)$ & $24(1.30)$ & $0.19(0.04)$ & $0.24(0.03)$ & $0.00^{*}(0.09)$ \\
ECM70 $_{\text {high }}$ & $4.6(1.20)$ & $23(1.10)$ & $0.16(0.04)$ & $0.15(0.03)$ & 0.80 \\
\hline
\end{tabular}

${ }^{1}$ CFHA = interval from calving to first high activity; DHA = duration of high activity; SHA = strength of high activity is based on the log-transformed mean of the two highest deviations between standardized activity and the smoothed activity; ECM70 = ECM production at DIM 70.

${ }^{2}$ Heritability of RR model for -0.4 and 0.4 on the environmental scale (the averages of the environmental scale in low and high production environments).

*The analysis did not converge because of a genetic correlation very close to unity. 
Table 5. Genetic correlations (SE) between levels and slopes of interval from calving to first high activity (CFHA) and ECM production at DIM 70 (ECM70) in bivariate random regression model

\begin{tabular}{llr}
\hline CFHA & ECM70 & Genetic correlation \\
\hline Level & Level & $0.05(0.12)$ \\
Slope & Level & $0.27(0.16)$ \\
Level & Slope & $-0.55(0.22)$ \\
Slope & Slope & $0.25(0.26)$ \\
\hline
\end{tabular}

between CFHA and ECM70 was generally weak, but was lowest around or slightly above average production levels. Genetic correlation between CFHA and ECM70 decreased with increasing the production level from 0.14 in the beginning of the environmental trajectory to a minimum value of 0.04 when the production level slightly above the average before increasing upward to a value of 0.13 in the end of environmental trajectory.

Estimates of genetic correlations between CFHA and ECM70 across environments from the MT analysis treating trait values in low and high production levels as separate traits are shown in Table 6 . The change in the genetic correlation between CFHA and ECM70 between low and high production levels was detected by MT analysis and BRRM. For the MT analysis, the genetic correlation between CFHA and ECM70 was relatively low in the high production level compared with the low production level, but these estimates were associated with high standard errors.

\section{DISCUSSION}

In this study, the additive genetic variance and heritability estimates for CFHA and ECM70 were heterogeneous as a function of the herd average ECM70 level. Genetic correlations of the same trait in low and high production environments were not significantly different from unity for any trait except for SHA. Moreover, genetic correlations between CFHA and ECM70 were heterogeneous as a function of herd average ECM70 level.

\section{Variance Components and Heritability Estimates from URRM}

The heritability estimate of CFHA in the average production environment was 0.11 , and was similar to the estimates obtained by other studies (Løvendahl and Chagunda, 2009; Ismael et al., 2015) with heritability estimates ranging between 0.12 and 0.18 . Furthermore, Tenghe et al. (2015) reported heritability estimate of 0.12 for the interval from calving to commencement of luteal activity using milk progesterone records from the Herd Navigator system, whereas the heritability
Table 6. Genetic correlations and their SE between interval from calving to first high activity (CFHA) and ECM in high and low production environment using bivariate random regression model (BRRM) and multiple-trait (MT) analysis ${ }^{1}$

\begin{tabular}{llcr}
\hline CFHA & ECM70 $^{2}$ & BRRM & \multicolumn{1}{c}{ MT } \\
\hline Low & Low & 0.09 & $0.29(0.20)$ \\
High & High & 0.04 & $-0.13(0.23)$ \\
\hline
\end{tabular}

${ }^{1}$ Genetic correlation of BRRM estimated between -0.4 and 0.4 on the environmental scale because these were the averages of the environmental scale in low and high production environments.

${ }^{2} \mathrm{ECM} 70=\mathrm{ECM}$ production at DIM 70.

estimate reported for CFI in the same study was 0.11 in Holstein cows from commercial dairy herds in the Netherlands. The DHA and SHA exhibited low heritability estimates in the average production environment. These estimates were consistent with the previously reported estimates (Løvendahl and Chagunda, 2009; Ismael et al., 2015) with heritability estimates ranging from 0.02 to 0.08 . For ECM70, the heritability in the average production environment was 0.18 , which was in agreement with previously reported estimates of ECM single test-day yield between 0.14 and 0.25 (Hüttmann et al., 2009; Hossein-Zadeh, 2012; Liinamo et al., 2012).

The decline in additive genetic variance and heritability estimates of CFHA with increasing herd production level (Figure 1) was also supported by the results of MT analysis (Table 4), where the heritability estimate for low-producing herds was $30 \%$ higher than the estimate for the high-producing herds. It was clear that the higher heritability estimate of the low-producing herds was mainly a reflection of larger genetic variance; the additive genetic variance for low-producing herds was $50 \%$ higher than the corresponding variance in the high-producing herds. These findings are in agreement with Strandberg et al. (2009), who reported that for CFI in UK Holstein, the heritability decreased with

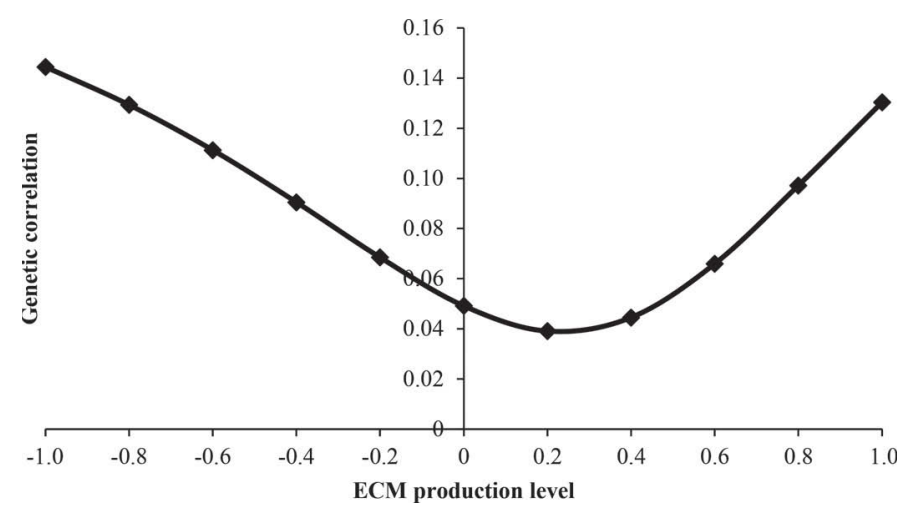

Figure 3. Genetic correlations between interval from calving to first high activity (CFHA) and ECM as a function of ECM production level. 
increasing herd milk production level. Furthermore, Haile-Mariam et al. (2008) reported that the heritability estimate of CFI in the low production level was more than twice the heritability estimate in the high production level (0.10 vs. 0.04 ), using the average herd lactation milk yield as an environmental descriptor for Holstein cows in Australia.

For DHA, the heritability estimate obtained by MT for the low-producing herds was more than twice the estimate for the high-producing herds; this difference was mainly due to the large difference in the estimates of genetic variance (Table 4). This trend in heritability was not detected by the URRM, where the slope term caused the model to fail to converge, thus leading to a constant heritability across environments.

The additive genetic variance and heritability estimates of ECM70 from URRM decreased with the increase in herd production level (Figure 2). This decrease was less observable in the results of MT analysis of low- and high-producing herds considering the standard error estimates (Table 4). It was clear that the higher heritability estimate of the low-producing herds was mainly due to larger genetic variance. This result is in contrast to the results obtained by Haile-Mariam et al. (2008), where the heritability estimate for milk yield in a high production level environment was 0.29 compared with 0.19 in a low production environment in Holstein cows in Australia. Furthermore, Kolmodin et al. (2004) reported higher heritability estimate for protein yield in the high-producing herds using a reaction norm model, where the heritability estimates ranged between 0.18 and 0.35 . In our study, the results of URRM for ECM70 do not seem to be an artifact of the random regression model, because the same trend was found in the MT analysis, albeit with a smaller difference. The difference could possibly be due to that the other studies analyzed 305-d yields and not test-day yield close to peak production, which could be more influenced by the test-day effect.

Heterogeneity of residual variances was only observed for CFHA and was very small, where the residual variance for the third class was only $2 \%$ higher than the residual variance in the first class, meaning that accounting for heterogeneity of residual variance for this trait only resulted in minor changes in heritability. This led to the conclusion that accounting for residual variance heterogeneity for the traits studied was not important, which is in accordance with the results of Strandberg et al. (2009).

Genetic correlations of the same trait measured in 2 different environments were used to indicate $\mathrm{G} \times \mathrm{E}$. For CFHA, DHA, and ECM70, as a general conclusion from the genetic correlations estimated from both URRM and MT, G $\times \mathrm{E}$ was not of great importance.
The results for CFHA were in agreement with previous research done on CFI using reaction norm models (Haile-Mariam et al., 2008; Strandberg et al., 2009). The genetic correlation of ECM70 between low and high production level was in agreement with the previously reported studies that used reaction norm models on milk and protein yield who found genetic correlations of $>0.85$ (Kolmodin et al., 2002; Hayes et al., 2003; Kolmodin et al., 2004; Haile-Mariam et al., 2008). For SHA, the genetic correlations between low and high production levels were 0.08 and 0.22 using the MT model and URRM, respectively, and clearly different from unity. However, these estimates were associated with high standard error estimates and might be biased downward because of the low heritability estimates of the traits and the small data set. This bias might lead to false positive existence of $\mathrm{G} \times \mathrm{E}$ (Sae-Lim et al., 2010). To overcome this problem, more data might be required for further validation of the obtained results.

The genetic correlations between the level and the slope for both CFHA and ECM70 were moderately negative $(-0.33$ and -0.47 , respectively). This negative correlation is more of a problem for CFHA because it indicates that cows with genetically shorter CFHA, which is desirable, were also more sensitive to changes in herd production level. This means that the continuous selection for shorter CFHA level will lead to a higher (positive) slope with respect to average herd ECM level, which might actually lead to a more flat reaction norm (less negative slope, going toward a positive slope and maybe going above zero). For EMC70, cows with genetically higher ECM70 production (which is desirable) were less sensitive to changes in herd production level.

\section{Results of Bivariate Random Regression Analysis of CFHA and ECM70}

The genetic correlation between CFHA and ECM70 was low across all environments but decreased slightly with increasing production level from 0.09 to 0.04 using BRRM with the lowest estimate slightly above the average environment. This decrease was too difficult to be confirmed using the MT analysis although it showed the same trend, but the estimates for genetic correlation estimates in low and high production environment were associated with high standard errors. The results of BRRM analysis are in agreement with Kolmodin et al. (2002) who reported that the genetic correlation between days open and protein yield as a function of average herd protein production became less unfavorable with increasing production level. Haile-Mariam et al. (2008) reported opposite results where the genetic correlation between the CFI and milk yield was zero 
in the low-producing herds compared with 0.38 in the high-producing herds. The current results might indicate that the unfavorable genetic correlation between CFHA and ECM70 could be decreased by providing a better level of the production environment. However, the difference between the genetic correlation estimates between CFHA and ECM70 in the low and high production environment was very small to support this conclusion.

\section{General Comments}

Use of activity monitor devices such as pedometer or activity tags as an indicator for the true estrus behavior such as the duration and strength of estrus is reported in many studies (Løvendahl and Chagunda, 2010; Dolecheck et al., 2015; Silper et al., 2015). The average of CFHA was $42.0 \mathrm{~d}$, DHA $8.9 \mathrm{~h}$, and SHA 1.08 ln-units. The average CFHA was lower than that obtained by Ismael et al. (2015) who reported an average CFHA of $49.5 \mathrm{~d}$ using the same algorithm of heat detection on a subset of the data used for the present study but close to the average obtained by Løvendahl and Chagunda (2010), who reported a mean CFHA of 44.0 d. For DHA and SHA, the averages were similar to those found by these studies.

In the current study, the heterogeneity of genetic variances of the traits across herd production levels might lead to different selection responses in different environments if selection is in the average environment using estimated breeding values (Falconer and Mackay, 1996). For example, Calus et al. (2005, 2006) reported higher selection responses for fertility and SCS in herds with on average poorer fertility and higher SCS. Furthermore, the heterogeneity of heritability estimates observed for the traits at different production levels can cause heterogeneity of accuracies of animals in different environments (Hill et al., 1983). This is regardless of whether there is substantial reranking across environments or not.

Previous studies performed on $\mathrm{G} \times \mathrm{E}$ of fertility traits as a function of the production environment found small $\mathrm{G} \times \mathrm{E}$ effect and large heterogeneity of genetic variances. For example, in Holstein cows in Australia and UK, the genetic correlation for calving interval between low and high production environment was 0.74 and 0.77 , respectively (Haile-Mariam et al., 2008; Strandberg et al., 2009). Other studies that used distinct production environments to investigate $G \times$ $\mathrm{E}$ for fertility traits by multitrait approaches found significant $G \times E$ effects. For example, Boettcher et al. (2003) found genetic correlation of 0.64 for calving interval between pasture-based herds and conventional herds in Canada, but this correlation was not signifi- cantly different from unity because of high standard error. Moreover, Kearney et al. (2004) found genetic correlation of 0.74 for days open between grazing and conventional herds in the United States. In this study, the genetic correlation of CFHA between low and high production environment using URRM was 0.74. This would indicate some reranking of animals across production environments. However, this was not a conclusive evidence of significant $\mathrm{G} \times \mathrm{E}$ because the genetic correlation between low and high production environments obtained from the MT model was not significantly different from unity. For further investigation of the potential reranking of sires across production environments, the breeding values of the top 5 sires in low, average, and high production environments were calculated from URRM, and only slight reranking of sires between different environments were found. The $\mathrm{G} \times \mathrm{E}$ interaction was clearly present for SHA, which might be problematic if selection was to be carried out for this trait; however, this trait is likely to be of less economic importance than CFHA.

\section{CONCLUSIONS}

The phenotypic expression of activity-based estrus traits was not affected by production environment in this study, but heterogeneous genetic variation was found for all traits as a function of production environment. The genetic correlation estimates of the fertility traits between low and high production environment showed little evidence of $\mathrm{G} \times \mathrm{E}$ existence. The genetic correlation between CFHA and ECM70 was unfavorable but weak, and decreased slightly with increasing production level, implying that the unfavorable genetic correlation between fertility and milk yield traits may be diminished in better production environments.

\section{ACKNOWLEDGMENTS}

This study is a part of the project "Nordic research network on animal genetic resources in the adaptation to climate change" funded by the AnGR-NordicNET (NordGen, Nordic Council of Ministers, Ås, Norway). The authors also acknowledge SEGES, Skejby, Denmark, for providing the data. The first author was enrolled in the Erasmus-Mundus joint doctorate European Graduate School in Animal Breeding and Genetics (Paris, France).

\section{REFERENCES}

Berry, D. P., F. Buckley, P. Dillon, R. D. Evans, M. Rath, and R. F. Veerkamp. 2003. Genetic parameters for body condition score, body weight, milk yield, and fertility estimated using random regression models. J. Dairy Sci. 86:3704-3717. 
Boettcher, P. J., J. Fatehl, and M. M. Schutz. 2003. Genotype x environment interactions in conventional versus pasture-based dairies in Canada. J. Dairy Sci. 86:383-389.

Boonkum, W., I. Misztal, M. Duangjinda, V. Pattarajinda, S. Tumwasorn, and S. Buaban. 2011. Short communication: genetic effects of heat stress on days open for Thai Holstein crossbreds. J. Dairy Sci. 94:1592-1596.

Calus, M. P. L., L. L. G. Janss, and R. F. Veerkamp. 2006. Genotype by environment interaction for somatic cell score across bulk milk somatic cell count and days in milk. J. Dairy Sci. 89:4846-4857.

Calus, M. P. L., J. J. Windig, and R. F. Veerkamp. 2005. Associations among descriptors of herd management and phenotypic and genetic levels of health and fertility. J. Dairy Sci. 88:2178-2189.

de Jong, G. 1995. Phenotypic plasticity as a product of selection in a variable environment. Am. Nat. 145:493-512.

Dodenhoff, J., L. D. Van Vleck, S. D. Kachman, and R. M. Koch. 1998. Parameter estimates for direct, maternal, and grandmaternal genetic effects for birth weight and weaning weight in Hereford cattle. J. Anim. Sci. 76:2521-2527.

Dolecheck, K. A., W. J. Silvia, G. Heersche Jr., Y. M. Chang, D. L. Ray, A. E. Stone, B. A. Wadsworth, and J. M. Bewley. 2015. Behavioral and physiological changes around estrus events identified using multiple automated monitoring technologies. J. Dairy Sci. 98:8723-8731.

Falconer, D. S., and T. F. C. Mackay. 1996. Introduction to Quantitative Genetics. 4th ed. Longman Group, Essex, UK.

Haile-Mariam, M., M. J. Carrick, and M. E. Goddard. 2008. Genotype by environment interaction for fertility, survival, and milk production traits in Australian dairy cattle. J. Dairy Sci. 91:4840-4853.

Hayes, B., M. Carrick, P. Bowman, and M. Goddard. 2003. Genotype $\mathrm{x}$ environment interaction for milk production of daughters of Australian dairy sires from test-day records. J. Dairy Sci. 86:37363744 .

Hill, W. G., M. R. Edwards, M.-K. A. Ahmed, and R. Thompson 1983. Heritability of milk yield and composition at different levels and variability of production. Anim. Sci. 36:59-68.

Hossein-Zadeh, N. G. 2012. Estimation of genetic parameters and trends for energy-corrected 305-d milk yield in Iranian Holsteins. Arch. Tierzucht 55:420-426.

Hüttmann, H., E. Stamer, W. Junge, G. Thaller, and E. Kalm. 2009 Analysis of feed intake and energy balance of high-yielding first lactating Holstein cows with fixed and random regression models. Animal 3:181-188.

Interbull. 2015. INTERBULL breeding values calculated August 2015 SEGES, Aarhus, Denmark.

Ismael, A., E. Strandberg, B. Berglund, M. Kargo, A. Fogh, and P. Løvendahl. 2016. Genotype by environment interaction for the interval from calving to first insemination with regard to calving month and geographic location in Holstein cows in Denmark and Sweden. J. Dairy Sci. 99:5498-5507.

Ismael, A., E. Strandberg, M. Kargo, A. Fogh, and P. Løvendahl. 2015. Estrus traits derived from activity measurements are heritable and closely related to the time from calving to first insemination. J. Dairy Sci. 98:3470-3477.

Kearney, J. F., M. M. Schutz, and P. J. Boettcher. 2004. Genotype × environment interaction for grazing vs. Confinement. II. Health and reproduction traits. J. Dairy Sci. 87:510-516.

Kolmodin, R., E. Strandberg, B. Danell, and H. Jorjani. 2004. Reaction norms for protein yield and days open in Swedish Red and
White dairy cattle in relation to various environmental variables. Acta Agric Scand. A Anim. Sci. 54:139-151.

Kolmodin, R., E. Strandberg, P. Madsen, J. Jensen, and H. Jorjani. 2002. Genotype by environment interaction in Nordic dairy cattle studied using reaction norms. Acta Agric Scand. A Anim. Sci. 52:11-24.

König, S., Y. M. Chang, U. U. v. Borstel, D. Gianola, and H. Simianer. 2008. Genetic and phenotypic relationships among milk urea nitrogen, fertility, and milk yield in Holstein cows. J. Dairy Sci. 91:4372-4382

Liinamo, A. E., P. Mantysaari, and E. A. Mantysaari. 2012. Short communication: Genetic parameters for feed intake, production, and extent of negative energy balance in Nordic Red dairy cattle. J. Dairy Sci. 95:6788-6794.

Løvendahl, P., and M. G. G. Chagunda. 2009. Short communication: Genetic variation in estrus activity traits. J. Dairy Sci. 92:46834688

Løvendahl, P., and M. G. G. Chagunda. 2010. On the use of physical activity monitoring for estrus detection in dairy cows. J. Dairy Sci. 93:249-259.

Madsen, P., and J. Jensen. 2010. A User's Guide to DMU, version 6, release 5. Faculty of Agricultural Sciences, Aarhus University, Denmark.

Miglior, F., B. L. Muir, and B. J. Van Doormaal. 2005. Selection indices in Holstein cattle of various countries. J. Dairy Sci. 88:12551263

Oseni, S., I. Misztal, S. Tsuruta, and R. Rekaya. 2004. Genetic components of days open under heat stress. J. Dairy Sci. 87:3022-3028.

Ravagnolo, O., and I. Misztal. 2002a. Effect of heat stress on nonreturn rate in Holsteins: Fixed-model analyses. J. Dairy Sci. $85: 3101-3106$

Ravagnolo, O., and I. Misztal. 2002b. Effect of heat stress on nonreturn rate in Holstein cows: Genetic analyses. J. Dairy Sci. 85:30923100

Sae-Lim, P., H. Komen, and A. Kause. 2010. Bias and precision of estimates of genotype-by-environment interaction: A simulation study. Aquaculture 310:66-73.

Schaeffer, L. R. 2004. Application of random regression models in animal breeding. Livest. Prod. Sci. 86:35-45.

SEGES. 2015. Årsstatistik Avl - 2014/15 (Annual Statistics Breeding - 2014/15), 30th ed. SEGES, Aarhus, Denmark.

Sewalem, A., G. J. Kistemaker, and F. Miglior. 2010. Relationship between female fertility and production traits in Canadian Holsteins. J. Dairy Sci. 93:4427-4434.

Silper, B. F., A. M. L. Madureira, M. Kaur, T. A. Burnett, and R. L. A. Cerri. 2015. Comparison of estrus characteristics in Holstein heifers by 2 activity monitoring systems. J. Dairy Sci. 98:3158 3165

Smith, J. W., L. O. Ely, W. M. Graves, and W. D. Gilson. 2002. Effect of milking frequency on DHI performance measures. J. Dairy Sci. $85: 3526-3533$

Strandberg, E., S. Brotherstone, E. Wall, and M. P. Coffey. 2009. Genotype by environment interaction for first-lactation female fertility traits in UK dairy cattle. J. Dairy Sci. 92:3437-3446.

Tenghe, A. M. M., A. C. Bouwman, B. Berglund, E. Strandberg, J. Y. Blom, and R. F. Veerkamp. 2015. Estimating genetic parameters for fertility in dairy cows from in-line milk progesterone profiles. J. Dairy Sci. 98:5763-5773. 